\section{The facilitating effects of mental rehearsal in the acquisition of rotary pursuit tracking}

\author{
EDNA I. RAWLINGS*† \\ University of Iowa, Iowa City, Iowa 52240 \\ IRVING L. RAWLINGS, STUART S. CHEN, and MARY DONIS YILK \\ Fort Hays Kansas State College, Hays, Kans. 67601
}

Two experiments were performed to test the hypothesis that mental rehearsal facilitates learning of rotary pursuit tracking. In Experiment 1, improvement in rotary pursuit tracking was compared for a physical practice group, a mental rehearsal group, and a no-practice control group. After 10 days of practice, the physical practice and mental rehearsal groups were equally proficient and both groups were superior to the no-practice control group. In Experiment 2, the rate of learning was faster for a group which mentally rehearsed during rest periods following physical practice than a group which performed a controlled task during the rest periods. The group engaging in combined mental and physical practice reached asymptote 2 days earlier than did the physical-practice-only group.

In 1943, Vandell, Davis, \& Clugson observed that, "Although the element of mental practice is being presented as a possible important factor in motor learning, it might as well be classified as a significant but uncontrolled variable [p. 243]." That statement remains true almost 30 years later. There is some evidence in the literature that mental rehearsal can facilitate motor learning (Clark, 1960; Harby, 1952; Twining, 1949; Vandell et al, 1943; Perry, 1939). The types of motor tasks that have been studied raise some question about the generality of this finding for all types of motor learning.

Of the few studies specifically designed to assess the effects of mental rehearsal on motor learning, most have used games and sport activities (Clark, 1960; Harby, 1952; Twining, 1949; Vandell et al, 1943). The amount of prior experience has not been controlled in these studies. Clark (1960) noted that the amount of prior experience in basketball was directly related to Ss' ability to benefit from mental rehearsal of the Pacific Coast one-hand foul shot. Unfortunately, in his study, age and experience were confounded.

Perry (1939) reported a study using several standard laboratory tasks. He compared the efficiency of learning five different tasks using physical or mental practice and concluded, rather arbitrarily, that imaginary practice was more effective with tasks that rely heavily on symbolic functions.

The principal problem for the

*The first two named authors take equal responsibility for the research reported in this paper.

tRequests for reprints should be sent to Edna I. Rawlings, 500 Newton Road. Iowa City, Iowa 52240. present study was the extent to which mental rehearsal would facilitate learning on the pursuit rotor, a task that has few symbolic components (Buxton \& Henry, 1939) and is a relatively novel task for Ss. In discussing the pursuit rotor, Snoddy (1938) remarked: "This type of learning is excellent because it begins at a very early level where the primary or stabilization type of growth is taking place and, unfortunately, this is not true of the vast majority of present day learning situations [p. 378]."

In some of the studies of mental rehearsal in motor learning, no-practice control groups were included to control for repeated measurement. Control Ss have not been found to improve on tasks; in performance measures than on the original criterion measure (Twining, 1949; Vandell et al, 1943; Perry, 1939). In these studies, control Ss have been dismissed after obtaining the initial baseline until the final performance tests. The expectations and motivation of control Ss may have differed from those of the experimental Ss, since the experimental Ss had had more contact with the experimental situation.

Two studies are reported in this paper. The first is a straightforward demonstration that mental rehearsal can facilitate learning of rotary pursuit tracking. In this study, control Ss, working on an irrelevant task, spent the same amount of time in the experimental setting as did experimental Ss. The second study shows that when Ss mentally rehearse as well as physically practice, learning is faster than with physical practice only. In both of these studies, mental rehearsal was operationally defined by fact, many do much worse on the final having Ss mentally picture the apparatus (which was not in view) and imagine themselves performing the task without actually making the motor movements.

\section{EXPERIMENT 1}

\section{Subjects}

The Ss were 24 female undergraduate volunteers from Fort Hays Kansas State College who were divided randomly into three experimental groups. Each $S$ was tested once per day for 10 days. Apparatus

The apparatus consisted of a Lafayette pursuit rotor moving at $60 \mathrm{rpm}$ and connected to a Hunter timer set to give $30 \mathrm{sec}$ of practice followed by a 30-sec rest interval. A standard timer was set to measure the Ss' total time on target for each trial to $.01 \mathrm{sec}$. In order to reduce resistance, the target and the tip of the stylus were cleaned after being used by each $\mathrm{S}$. The speed of the apparatus was checked twice per day.

\section{Procedure}

For the first day, all Ss were instructed to practice tracking with their preferred hands for 25 trials. During the $30-\mathrm{sec}$ rest period, Ss were instructed to read aloud from a color list. From the second through the ninth day, Ss in Group 1, physical practice, practiced tracking for 25 trials. During the rest interval, Group 1 Ss read the names of common colors from a list at the rate of one color per second. Ss in Group 2, mental rehearsal, were taken into an adjoining room and instructed to mentally practice the tracking task. These Ss were encouraged to visualize the apparatus and the movement required in tracking. During the daily session, Ss were to mentally practice the task for $30 \mathrm{sec}$, followed by $30 \mathrm{sec}$ of color naming. Group $3 \mathrm{Ss}$, control Ss, were given 25 trials, $30 \mathrm{sec}$ each, of color naming, followed by a 30-sec rest interval. On Day 10, all groups were retested on the rotary pursuit task for 25 trials. The total time on target for the 25 trials was averaged for each $S$ for Day 1 and Day 10, respectively.

Results and Discussion

The mean total time on target of the three groups for Days 1 and 10 was analyzed by a simple repeated measures analysis of variance. The results of that analysis showed that the $F$ ratios for the following sums of squares were significant at $p<.001$ level of confidence: between-groups S S $(F=41.92, \quad \mathrm{df}=2 / 21)$, between-days SS $(F=1,420.83$, $\mathrm{df}=1 / 21$ ), and the Group by Days interaction $\mathrm{SS}(\mathrm{F}=155.19, \mathrm{df}=2 / 21)$.

The Groups by Days interaction is of particular relevance in interpreting the results of this study. This interaction is graphed in Fig. 1. As 


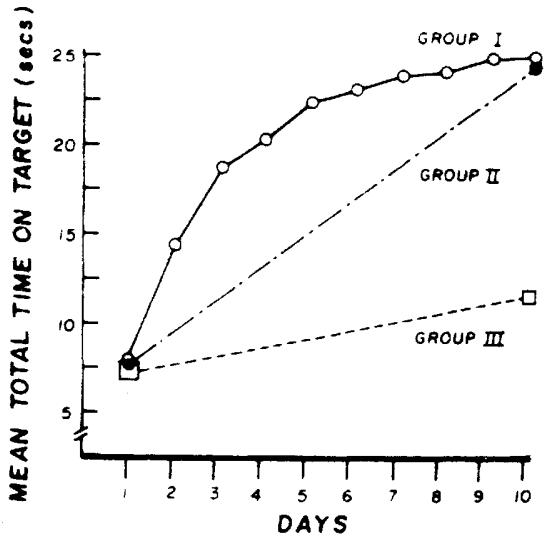

Fig. 1. Mean total time on target for Day s 1-10 for Group 1 (physical practice), Group 2 (mental rehearsal), and Group 3 (control).

Fig. 1 shows, the means of the groups did not differ initially on Day 1 , and all groups improved from Day 1 to Day 10. The greatest improvement was in Groups 1 and 2. The mean time on target for these two groups was almost identical on Day 10. On Day 10, the performance level of Groups 1 and 2 appeared higher than that of Group 3 . Statistical confirmation for all of the above observations was obtained by analyzing means of the Groups by Days interactions with the Duncan multiple range test $(p<.05)$.

The results of this investigation confirm the hypothesis that mental rehearsal can facilitate learning of rotary pursuit tracking. Under the specific conditions of this experiment, mental rehearsal was as effective as physical practice in acquiring proficiency on the tracking task. The study also shows that mental rehearsal can be effective even with a task that does not have a particularly significant cognitive component.

The lower final performance of the control group indicates that it is the active mental rehearsal rather than time lapse perse that is primarily responsible for the level of performance demonstrated by the mental rehearsal group on Day 10 . The significant improvement in motor tracking performance from pretest to posttest by the control group has not been demonstrated in cited studies. This improvement may in part be due to the task used in the present investigation. Apparently significant learning occurred after relatively short periods of practice with this task. Another factor contributing to improvement by the control group may have been equating the amount of time spent in the experimental situation by the control and experimental Ss.

\section{EXPERIMENT} Subjects

The Ss were 20 male freshman volunteers from introductory basic study courses at Fort Hays Kansas State College.

\section{Apparatus}

The apparatus was the same as that described in Experiment 1. Procedure

The Ss were assigned randomly to one of two groups: Group 1 (motor practice + mental rehearsal during rest period) or Group 2 (motor practice + color naming during rest period). During the first session, Ss were instructed on how to hold the stylus and perform the rotary pursuit tracking task. The general arrangements for a practice session were as follows: the groups were to practice and rest alternately, as E indicated. During the rest interval, Group 2 Ss were asked to read a list of 14 common colors, reading approximately one color per second. Ss in Group 1 were instructed not to look at the apparatus and to spend the rest interval mentally rehearsing the task they had just performed. Ss in both groups were told that they would be required to return to the lab for 10 days and that the outlined procedure would be the same each day. All Ss received 25 trials per day (30 sec practice on the task followed by a 30 -sec rest interval). Total time on target over the 25 trials for each of the Ss was averaged to provide daily mean time on target.

\section{Results and Discussion}

Mean total time on target is plotted as a function of days of practice in Fig. 2. Inspection of Fig. 2 indicates that mean total time on target for Group 1 (motor practice + mental rehearsal) is somewhat higher than for Group 2 (motor practice + color naming) for every day of testing. By defining asymptote as the point at which a group shows less than 1 sec mean improvement between days, Group 1 reached asymptote on Day 6, while Group 2 did not reach asymptote until 2 days later, on Day 8.

The mean total time on target for each group over the 10 days was analyzed by an extended Alexander trend analysis of variance (Grant, 1956). Between-individual means was highly significant, reflecting significant individual differences $\quad(\mathrm{F}=76.324$, $\mathrm{df}=18 / 108, \mathrm{p}<.001)$. In addition, the overall trend was significant, suggesting that the overall average score varies from stage to stage during acquisition. Partitioning the overall trend into its components yielded a significant linear component $(\mathrm{F}=290.525, \mathrm{df}=1 / 18, \mathrm{p}<.001)$, a significant quadratic component $(\mathrm{F}=209.865, \quad \mathrm{df}=1 / 18, \quad \mathrm{p}<.001)$, and a significant cubic component $(\mathrm{F}=89.371, \quad \mathrm{df}=1 / 18, \quad \mathrm{p}<.001)$. When all three components are

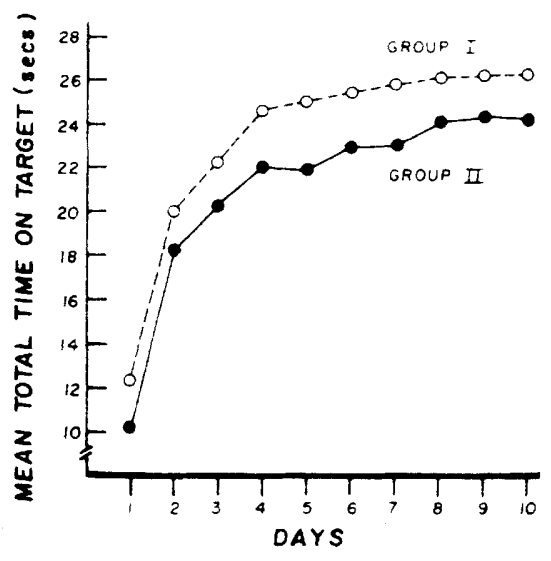

Fig. 2. Mean total time on target for Days 1-10 for Group 1 (motor practice + mental rehearsal during rest period) and Group 2 (motor practice + color naming during rest period).

significant, the conclusion would be that the overall trend is a curve which contains both a maxima and a minima (Myers, 1962).

The between-group quadratic was significant, indicating that the best-fit curve would be a quadratic. This supports the impression based on Fig. 2, i.e., that Group 1 achieved asymptote significantly earlier than did Group 2.

The results of this study again confirm the hypothesis that mental rehearsal can aid the acquisition of rotary pursuit tracking. The faster acquisition by the mental-rehearsal/ physical-practice group compared to the physical-practice-only group suggests an efficient technique for speeding the learning process in the development of a motor skill. A research question of practical importance would be to assess the most effective combinations of the two modes of practice for a particular task.

\section{GENERAL DISCUSSION}

Although there is evidence that mental rehearsal can facilitate motor learning, the nature of mental rehearsal in motor tasks is not understood. Perry (1939) concluded that mental rehearsal was synonymous with symbolic rehearsal. He inferred this from the types of tasks on which Ss showed the greatest improvement with mental rehearsal. Even if this conclusion was valid for his study, one could not assume that mental rehearsal of motor skills always involves verbalization. Clark (1960) reported that visual imagery was essential in mentally rehearsing the Pacific Coast one-hand foul shot. He noted that Ss who were better at visualizing the task profited more from mental rehearsal instructions. On the other hand, Twining (1949) and Vandell et al (1943) speculated that covert muscle 
potentials (kinesthetic imagery) occurring during so-called mental rehearsal were related to the subsequent improvement in motor performance.

The research reported in this paper was not designed to inquire into the nature of mental rehearsal. However, the instructions were biased in the direction of visual imagery. Also, several $S s$ in the mental rehearsal conditions voluntarily reported that it was easy to "see" themselves performing the tracking task. A predominately verbal strategy is adaptable when rehearsing tasks high in symbolic components, while a predominately visual or kinesthetic strategy is adaptable when rehearsing tasks high in perceptual motor components. The first two named authors are in the process of designing research to help clarify the nature of mental rehearsal in motor skills. Mental rehearsal is probably not a unitary phenomenon. Several factors which may be important in the mental rehearsal of motor skills are type of task, the cognitive style of the learner, and the experimental instructions for mental rehearsal.

\section{REFERENCES}

BUXTON, C. E., \& HENRY, C. E Retroaction and gains in motor learning: I. Similarity of interpolated tasks as a factor in gains. Journal of Experimental Psychology, 1939, 25, 1.17.

CLARK, L. The effect of mental practice on the development of a certain motor skill. Research Quarterly, 1960, 31, 560-569.

GRANT, D. A. Analy sis-of-variance tests in the analysis and comparison of curves. Psychological Bulletin, 1956, 53,
141-154.

HARBY, S. F. Comparison of mental and physical practice in the learning of physical skill (Pennsylvania State College). U.S.N. Instructional Film Research Reports, Special Devices Center. Port Washington, Long Island, N.Y. Technical Report No.SDC 269-7-27, 1952. P. 11.

MYERS, F. E. Statistical analy'sis. Englewood Cliffs, N.J: Prentice-Hall. 1962.

PERRY, N. M. The relative efficiency of actual and imaginary practice in five selected tasks. Archives of Psychology, 1939,34 , No. 243 .

SNODDY, G. S. A reply to Dore and Hilgard. Journal of Experimental Psychology, 1938, 23, 375-385.

TWINING, E. Mental practice and physical practice in learning a motor skill Research Quarterly, 1949, 20, 432-435.

VANDELL, R. A., DAVIS, R. A., \& CLUGSTON, N. A. Function of mental practice in the acquisition of motor skills. Journal of General Psychology, 1943, 29 . 243-250. 